\title{
DORSAL ONLAY BUCCAL MUCOSAL GRAFT URETHROPLASTY FOR BULBAR URETHRAL STRICTURE- EXPERIENCE OF 20 CASES
}

\author{
AL-ASAD H ${ }^{1}$, BHUIYAN AKMM ${ }^{2}$, ISLAM MN ${ }^{3}$, KARMAKER U ${ }^{4}, \mathrm{CHOWDHURY} \mathrm{SA}^{5}$, SAHA PK ${ }^{6}$, \\ HOSSAIN AKMS $^{7}$, ALAM SMM ${ }^{8}$
}

\begin{abstract}
Objective: To assess the success of buccal mucosal graft (BMG) urethroplasty by the dorsal onlay technique in bulbar urethral stricture.

Materials and Methods: Fromuly 2008 to June 2010, twenty patients with anterior urethral strictures weremanaged by dorsal onlay BMG urethroplasty. After voiding trial, they were followed up at 3 weeksand 3 months with history, physical examination, uroflowmetryand retrograde urethrogram (RGU) if required. Patients were furtherfollowed-up at 3 months interval with uroflowmetry and retrograde urethrogram (RGU) if required. Successfuloutcome was defined as normal voiding with no surgical intervention after catheter removal.
\end{abstract}

Results: Mean stricture length was $3.5 \pm 0.8 \mathrm{~cm}$ and mean follow up was 12 months (range 6 to 24 months). Twopatients were found to develop stricture at anastomotic site, during followup and required optical internal urethrotomy and was considered as failure. One patient developed wound infection which resolved after regular dressing. Success rate was 90\%.

Conclusion: Dorsal onlay BMG urethroplasty is a simple technique with good surgical outcome.

Key words: Urethral stricture, Buccal mucosal graft (BMG), Retrograde urethrogram (RGU), Voiding cystourethrogram (VCUG), Optical internal urethrotomy (OIU).

J Dhaka Med Coll. 2014; 23(2) : 175-178.

\section{Introduction}

Urethral stricture is fibrotic narrowing of urethral lumen; fibrosis usually extends into the surrounding corpus spongiosum causing spongiofibrosis. Urethral reconstruction remains a challenge in modern urology practice. The treatment of urethral strictures varies according to location, length, depth and density of the stricture. Optical internal urethrotomy (OIU) may be useful for short annular strictures, but this procedure is associated to a very high recurrence rate. ${ }^{1}$ Urethral reconstruction with excision of the strictured segment and end-to-end anastomosis is successful in more than 95\% of patients with a stricture of up to $2 \mathrm{~cm}$ in length. ${ }^{2}$ Patients with long strictures $(>2 \mathrm{~cm}$ in length) are not suitable for end-to-end urethroplasty due to the risk of postoperativechordee formation. ${ }^{3}$ Substitution urethroplasty is ideal for the management of long anterior urethral strictures. The ideal material for substitution urethroplasty remains controversial. ${ }^{4}$ Urethral substitution has long been accomplished by using genital skin flaps, grafts of genital or extragenital tissue. ${ }^{5}$ Currently, buccal mucosa graft substitution urethroplasty is the most preferred

1. Dr. Hafiz Al-Asad, Registrar, Department of Urology, Dhaka Medical College Hospital, Dhaka.

2. Dr. A.K.M. Musa Bhuiyan, Assistant Professor, Department of Urology, Dhaka Medical College \& Hospital, Dhaka.

3. Dr. Md. Nazmul Islam, Resident Surgeon, Department of Urology, Dhaka Medical College Hospital, Dhaka.

4. Dr. Uttam Karmaker, Assistant Professor, Department of Urology, Dhaka Medical College \& Hospital, Dhaka.

5. Dr. Md. Shafiqul Alam Chowdhury, Associate Professor, Department of Urology, Dhaka Medical College \& Hospital, Dhaka.

6. Dr. Prodyut Kumar Saha, Associate Professor, Department of Urology, Dhaka Medical College \& Hospital, Dhaka.

7. Dr. AKM Shahadat Hossain, Associate Professor, Department of Urology, Dhaka Medical College Hospital, Dhaka

8. Prof. S. M. MahbubAlam, Professor \& Head, Department of Urology, Dhaka Medical College \& Hospital, Dhaka. Correspondence: Dr. Hafiz Al-Asad, Registrar,Department of Urology, Dhaka Medical College Hospital, Dhaka. Cell Phone: +8801712179043, Email: hafizalasad34@yahoo.com 
option for long bulbar urethral strictures. Buccal mucosa offers the advantages of being accustomed to a wet environment, having good vascularity, hair less, easy to harvest, thick epithelium making it easy to handle and less chance of graft contracture, having a thin lamina propria allowing early inosculation, reduced rate of pseudo-diverticulum formation. ${ }^{4}$ Weather to place the graft dorsally, ventrally or laterally is still controversial. Dorsal onlay graft procedure provides the advantages of better mechanical support by the corporal bodies with fewer incidences of sacculation and fistula formation but this approach may damage erectile function and the bulbar arteries when the dissection from the corpora needs to be very proximal. ${ }^{6}$ In our study, we describe our experience with dorsal buccal mucosal graft (BMG) urethroplasty for long segment bulbar urethral stricture.

\section{Materials and Methods}

FromJuly 2008 to June 2010, twenty patients with long bulbar urethral stricture were managed by single stage urethroplasty with a dorsalonlay patch BMG. Each patient was evaluated with history, physical examination, uroflowmetry, imagingstudy with retrograde urethrogram (RGU) and voidingcystourethrogram (VCUG) and other routine investigations required for anaesthetic fitness. All the patients were selected purposively according to the selection criteria that were, patients having primary and recurrent stricture of anterior urethra involving the bulbar urethra, stricture length $2 \mathrm{~cm}$ to $6 \mathrm{~cm}$, patients with significant lower urinary tract symptoms and patient given consent for operation and record for study purpose. Stricture involving posterior and distal penile urethra and with oral pathology were excluded. Ethical committee's approval was taken to performthe study.Operation was performed under generalanesthesia with nasotrachealintubation and the patient wasput in exaggerated lithotomy position. Operation wasdone in a 2-team approach-one team engaged in urethral procedure and other team in harvesting thebuccal mucosa. Through a midline perineal incision, the bulbocavernosus muscle was divided exposing thecorpus spongiosum of the anterior urethra. Then thebulbar urethra was easily dissected from corporacavernosa. Then the strictured segment of the urethra wasidentified. The other team then harvested the buccalmucosal graft of adequate length, from the inner cheekarea below the Stensen's duct without injuring it.Lignocaine (2\%) with adrenaline (1:200000) wasinjected into the edges of the desired graft length beforeharvesting to get better hemostasis. Graft donor site is closed with continuous 4-0 chromiccatgut sutures to achieve good hemostasis. The graft was then defatted and tailored to its proper size.The dissected urethra was rotated $180^{\circ}$. Thedorsal surface of the strictured segment was exposedand opened vertically extending the incision for about $1 \mathrm{~cm}$ both proximally and distally into the normalurethral lumen. The proximal and distal urethral lumens of the urethra were calibrated. The right margin of the graft was sutured with the urethral margin using 5-0 polyglactinsuture. Foley catheter was inserted through the urethra into the urinary bladder. Then the urethra was rotated back to its original position and left margin of the urethral mucosa was sutured to the graft using 5-0 polyglactin continuous suture. Few interrupted stitches were given to fix the graft with the corpora cavernosa along the midline dorsally.Suprapubic catheterization was done in all patients. The patient was maintained on antibiotics until the catheter was removed. Three weeks after the operation the urethral catheter was removed if patient could void well then the suprapubic catheter was removed on the next day. All the patients were advised to visit at outpatient door on 3 weeks and on 3 months for follow up. During follow up patient's history, physical examination, uroflowmetry were done. If uroflowmetry showed significant obstruction then retrograde urethrogram (RGU) and voiding cystourethrogram (VCUG) was done. A successful outcome was defined as normal voiding with no need of any kind of surgical inervention. Patientswere further followed-up at 3 months interval with uroflowmetryand RGU and VCUG if required. 


\section{Results}

Total 20 patients (mean age $42.6 \pm 10.2$ years) were underwent BMG urethroplastyby dorsal onlay graft between July 2008 to June 2010 . Most of the patients presented with poor flow of urine, some presented with per-urethral discharge and few of them presented with acute retention of urine.Mean stricture length was $3.5 \pm 0.8 \mathrm{~cm}$. Among the patients the cause of stricture were 11 inflammatory, 7 idiopathic and 2 were iatrogenic that were catheter induced trauma. Before surgery mean peak urinary flow rate was $8.9 \pm 2.5 \mathrm{ml} / \mathrm{sec}$. Mean operative time was $110 \mathrm{~min}$ (range 100 to 165 min) and mean follow- up 12 months(range 6 to 24 months). All patients requiredperoperative blood transfusion but no patients required it postoperatively. Nineteen patients were discharged on $4^{\text {th }}$ post-operative day, only one patient how developed wound infection was managed successfully with change in antibiotics as per wound swab culture sensitivity test and regular dressing and was discharged on $14^{\text {th }}$ post-operative. On urethral catheter removal of that patient he could void well and needed no intervention. On follow up peak urinary flow rate improved significantly. At 3 weeks and at 3 months the mean peak urinary flow rate was $18.9 \pm 5.1$ and $24.0 \pm 8.9$ $\mathrm{ml} / \mathrm{sec}$ respectively. Two patients developed stricture at proximal anastomotic site which was addressed during follow up and required optical internal urethrotomy and was considered as failure. In our series the mean follow up was 12 months (range 6 to 24 months).

\section{Discussion}

Urethral strictures were documented in ancient literature dating from Greek and Egyptian period. Continuous attempts are made in different parts of the world in different centers to find out an ideal method of treatment according to the merit of individual type of stricture. Significant progress made over the last 30 years. ${ }^{7}$ Long anterior urethral stricture ( $>2 \mathrm{~cm}$ long) should be treated with substitution urethroplasty to avoid postoperative chordee formation. ${ }^{3}$ Substitution urethroplasty may be a patch graft or tube graft. $^{8,9}$ Free skin grafts used as patch or tubegraft in substitution urethroplasty are associated withcomplications like graft shrinkage, diverticulumformation and recurrent stricture, although results ofpatch grafts are better than tube grafts ${ }^{10-12}$ Humby was the first to use buccal mucosafor urethral reconstruction in a series of single stage hypospadias repair. However, BMG urethroplastyhas emerged as a popular technique in 1990s. Whether to place the graft dorsally, ventrally orlaterally is still controversial now. Ventral onlay graftis more prone to fistula formation, sacculation anddiverticula formation leading to urinary stasis and ejaculatory dysfunction. ${ }^{4}$ On the other hand, dorsalonlay graft procedure for the anterior urethralstricture provides the advantages of bettermechanical support by the corporal bodies for thegraft's better take up, with less incidence ofsacculation and fistula formation. ${ }^{6}$, ${ }^{13}$ It has beenreported that dorsally placed graft can do betterbecause of better mechanical support for the graftand a richer vascular bed from the underlyingcorporal bodies. ${ }^{8}$ In different series, dorsal onlayBMG urethroplasty has shown a success rate from $87.5 \%$ to $100 \%$ with a follow-up ranging from 22 to 41 months. ${ }^{14,15}$ Recently, Barbagli et al. published a retrospective study of 50 cases withbulbar urethral stricture where buccal mucosal grafturethroplasty were done. ${ }^{16}$ In their study, graftswere placed as ventral, dorsal and lateral onlay in 17,27 and 6 patients respectively. After a meanfollow-up of 42 months, placement of graft intoventral, dorsal or lateral surface of the bulbar urethrashowed the similar success rate. In our series of 20 cases, only two patients developed re-stricture at proximal atanastomotic sites. One patient developed stricture within 3 months of operation and another one showed evidence of stricture on RGU after 6 months of operation. These two $(10 \%)$ were considered as failure, because these patients developing stricture after BMGurethroplasty and needed surgical intervention that is optical internal urethrotomy. In our series the success rate was $90 \%$ which was nearly similar to the other studies. ${ }^{14,15}$ Our mean follow-up was long enough 12 months (range 6 to 24 months). 


\section{Conclusion}

In the present study, it was observed that dorsal BMG urethroplasty is a reliable and satisfactory procedure to manage long bulbar urethral strictureswith minimum complications. Harvesting the graft is simple. Few cases, considered asfailure with stricture formation can be managed with optical internal urethrotomy.

\section{References}

1. Heyns CF, Steenkamp JW, DeKock ML, Whitaker P. Treatment of male urethral strictures: is repeateddilation or internal urethrotomy useful? J Urol 1998;160: 356-8.

2. Webster GD, Robertson CN. The vascularized skinisland urethroplasty: its role and results in urethralstricture management. J Urol 1985; 133: 31-3.

3. Gupta NP, Ansari MS, Dogra PN, Tandon S. Dorsalbuccal mucosal graft urethroplasty by a ventral sagittalurethrotomy and minimal-access perineal approach foranterior urethral stricture. BJU Int 2004; 93: 1287-90.

4. Bhargava S, Chapple CR. Buccal mucosalurethroplasty: is it the new gold standard? BJU Int2004;93: 1191-3.

5. Morey AF, McAninch JW.Techniques of harvesting buccal mucosa for urethral reconstruction. J Urol1996; 155: 1696.

6. Iselin $\mathrm{CE}$, Webster GD.Dorsal onlay graft urethroplasty for repair ofbulbar urethral strictures.J Urol1999; 161: 815-8.
7. Jordan GH, Schlossberg SM. Surgery of the penis and urethra. In: Wein AJ, Kavoussi LR, Novick AC, Partin AW, Peter CA. eds. Campbell's Urology. $9^{\text {th }}$ ed. Philadelphia: Saunders. 2007; p.1023-97.

8. Barbagli G., Palminteri E., Rizzo M. Dorsal onlay graft urethroplasty using penile skin or buccal mucosa in adult bulbourethral strictures. J Urol 1998; 160: 1307-9.

9. Brannan W, Ochsner MG, Fuselier HA, Goodlet JS. Free full thickness skin graft urethroplasty for urethral stricture: experience with 66 patients. J Urol 1976; 115: 677-80.

10. Orandi A. One-stage urethroplasty. Br J Urol 1968; 40: 717-9.

11. Morey AF, McAninch JW. Technique of harvesting buccal mucosa for urethral reconstruction. J Urol 1996; 155: 1696-7.

12. Venn SN, Mundy AR. Early experience with the use of buccal mucosa for substitution urethroplasty. Br J Urol 1998; 81: 738-40.

13. Barbagli G, Selli C, Tosto A, Palminteri E. Dorsal freegraft urethroplasty. J Urol 1996; 155: 123-6.

14. Dubey D, Kumar A, Bansal P, Srivastava A, Kapoor R, Mandhani A, et al.: Substitution urethroplasty for anterior urethral strictures: a critical appraisal of various techniques. BJU Int 2003; 91: 215-8.

15. Pansadoro V, Emiliozzi P, Gaffi M, Scarpone P, DePaula F, Pizzo M. Buccal mucosa urethroplasty in the treatment of bulbar urethral strictures. Urology2003; 61: 1008-10.

16. Barbagli G, Palminteri E, Guazzoni G, Montorsi F, Turini D, Lazzeri M. Bulbar urethroplasty using buccal mucosa grafts placed on the ventral, dorsal or lateral surface of the urethra: are results affected by the surgical technique?. J Urol 2005; 174: 955-7. 